\title{
Design and Construction of an Electric Guitar Body Made of Carbon Composite
}

\author{
Radoslav Vandžura, Vladimír Simkulet, Michal Hatala \\ Faculty of Manufacturing Technologies with a seat in Presov, Technical University of Kosice, \\ Bayerova 1, 08101 Presov, Slovakia
}

\begin{abstract}
This paper presents the selection of technology, technological and working procedures to construct the body of an electric guitar (Stratocaster type.). The used material for the electric guitar construction was carbon composite material offset by standardly used components. The carbon composite was chosen because of its excellent properties suitable for guitar construction. Described and used technologies were Manual Wet Lamination Technology and Vacuum Bag Molding (VBM) technology, and both are affordable and uncomplicated methods.
\end{abstract}

Keywords - Electric guitar, Carbon fibre, Composite materials, VBM, Vacuum Bag Molding.

\section{Introduction}

The electric guitar has undergone various modifications since its inception. Predominant material for its production is wood or wood composite. The next logical steps in construction development are experimentation and the use of new technologies and materials.

DOI: $10.18421 /$ SAR43-01

https://doi.org/10.18421/SAR43-01

Corresponding author: Radoslav Vandžura, Faculty of manufacturing technologies with the seat in Presov, Technical university of Kosice, Bayerova 1, 08001 Presov, Slovakia.

Email: radoslav.vandzura@tuke.sk

Received: 06 May 2021.

Revised: 05 July 2021.

Accepted: 12 July 2021.

Published: 23 September 2021.

C 2021 Radoslav Vandžura, Vladimír Simkulet licensed under the CC BY-NC 4.0.

The article is published with Open Access at www.sarjournal.com
One of possibilities is the use of modern available materials and technologies such as carbon fibre and materials such as a mixture of carbon fibres and resins, which have interesting mechanical and acoustic properties. [1], [2], [3] Modernization of traditional materials and technological procedures can also be applied in the construction of other musical instruments. Carbon composite appears to be a suitable material mainly due to various positive properties such as reducing weight, increasing strength, increasing resistance to chemical influences, corrosion, and so on. Hand in hand with modernization is the preservation of the characteristic design and especially the sound properties of the instrument [4]

\section{History of Electric Guitar}

The history of the electric guitar as such dates to early 20th century. In 1910, the first patents for electric guitar were created, which have modified telephone transmitters implemented in the body. In the 1920 s, the first instruments were created to use carbon microphones to sense vibrations. They were attached to the guitar bridge at the top. Further experimentation in the 1930s can be described as the date of the invention of the electric guitar as we know it today. Electric guitars were initially designed by acoustic guitar manufacturers and other musical instrument manufacturers. In this era, the demand for a guitar with a tinted sound grew and the first electric guitars were used mainly in jazz. Electric guitars are acoustic guitars complemented by an electromagnetic pickup with a transducer. [5], [6], [7]

\section{Principle of Operation and Construction of Electric Guitar}

The electric guitar is designed and constructed to produce an output signal to the vibration of the strings using electromagnetic sensors. The string vibrates during playing, the sensor placed under the strings of the guitar absorbs vibrations and induces an electric current in the coil of the sensor. The 
signal from the pickups is further adjusted and amplified employing amplifiers.

The basic parts of an electric guitar are described in Figure 1.

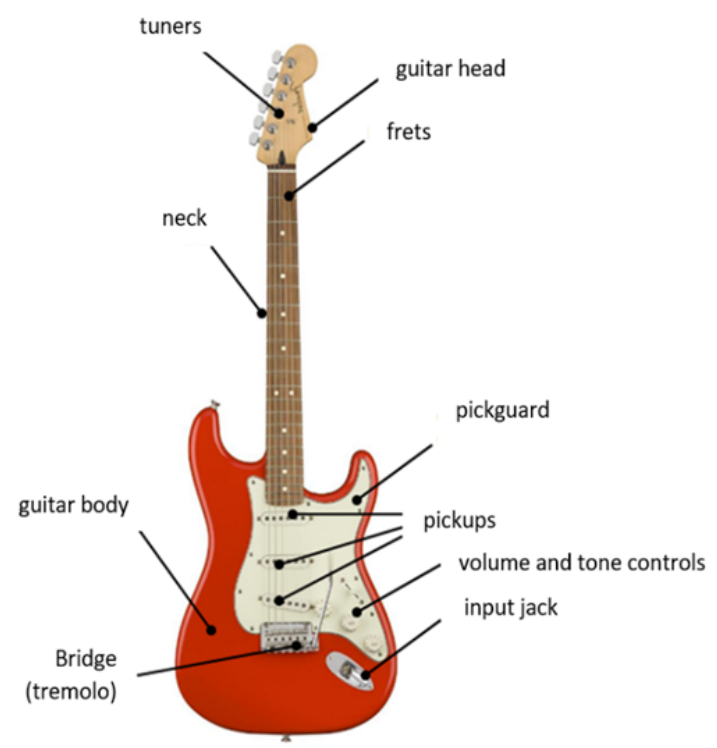

Figure 1. Basic parts of an electric guitar (Fender Stratocaster) [9]

Electric guitars with a solid body do not have a soundboard to amplify vibrations from the strings. Pickups and amplifier with speaker provide amplification of vibrations from the strings. They are made of hardwood with a hard finish. The wood species from which the guitars are made affect the sound properties of the guitar, its quality and, most importantly, the price. The most used wood for production is mahogany, American ash, alder, agate, walnut, and others. The solid body is complemented by a top plate with a more visible drawing of wood [5] [8].

\section{Hand lay-up Technology}

This method is used mainly in the production of car body parts, in the production of various prototypes, in the production of guitar moulds by copying models for further lamination, and most importantly, it is also used to produce carbon composites. The production of components by this method (Figure 2) is undemanding, inexpensive and various sizes of components and moulds can be produced. Separation material such as wax, various types of separators and their combinations, is applied to the mould. The main purpose of the separator is that the composite component does not stick to the mould and can be removed from the mould without problems. After applying and drying the separator, a layer of resin is applied to the mould. A layer of fabric is then deposited, which is saturated with resin using a brush or laminating roller. The process of depositing and saturating the layers is repeated until the desired number of layers is reached. After curing, the composite component can be removed from the mould and further modified. Various sources and procedures mention the use of gelcoat as the first layer that is creating a smooth surface for the product. [10], [11].

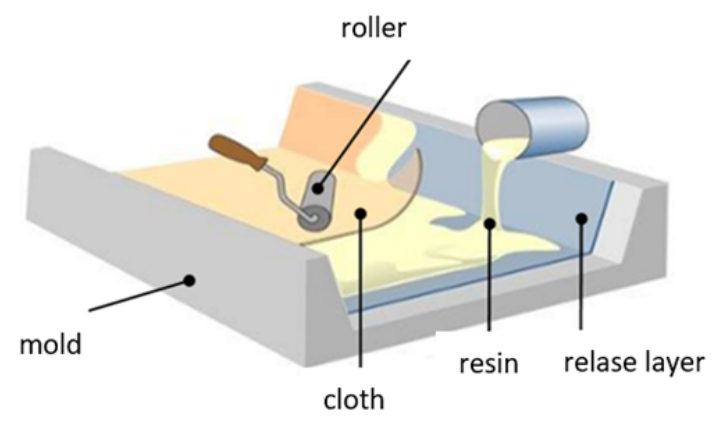

Figure 2. Hand lay-up technology scheme [10]

\section{VBM method- Vacuum Bag Moulding ethod}

This technology (Figure 3) directly follows the technology of manual wet lamination. The procedure for layering the composite material is the same except that in this technology, a perforated separating film and a layer of absorbent material are placed on the supersaturated layers by resin weaving. The mould with these layers is placed in a vacuum bag and the air is sucked off. The absorbent fabric absorbs excess resin through the perforated film. The vacuum compresses individual layers of the composite and removes excess air and resin. [11] [12]

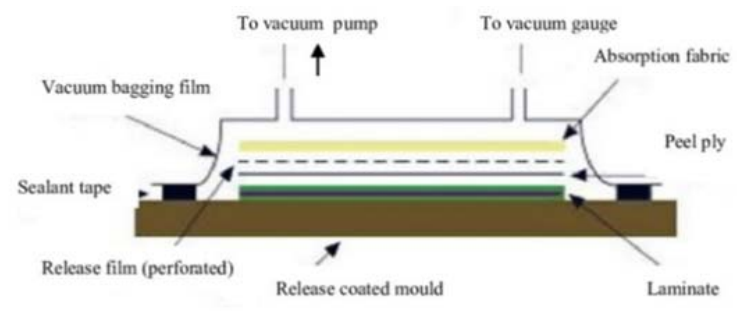

Figure 3. VBM technology scheme [12]

\section{The Material Used for Carbon Composites}

Carbon fibre fabrics: Carbon fibres have the widest spectrum of mechanical properties at a relatively low density. Carbon fibre laminates are characterized by high hardness and strength. Their endurance under dynamic load is excellent and electrically conductive. They are most often used in the production of parts for aircraft, racing vehicles or sports equipment. The suitability for use depends on the construction of the carbon fabric.

The following fabrics were used for guitar parts production: 
- KORDCARBON fabric $200 \mathrm{~g} / \mathrm{m}^{2}-$ Twill weave (Figure 4)

- KORDCARBON fabric $160 \mathrm{~g} / \mathrm{m}^{2}$ - Plain weave (Figure 5)

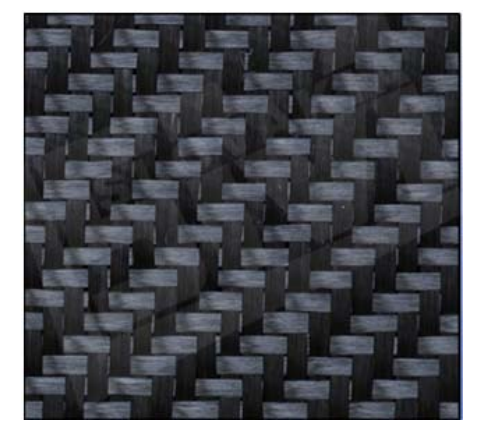

Figure 4. Twill weave carbon fibre

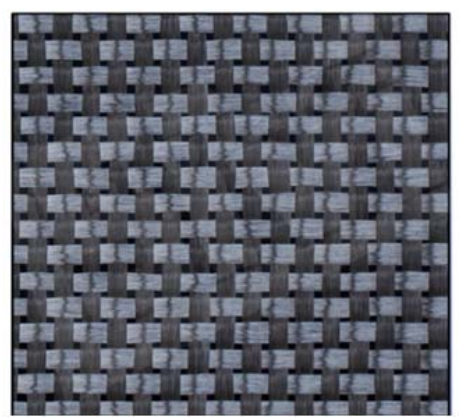

Figure 5. Plain weave carbon fibre

Epoxy resin Letoxide PR220 + hardener EM315: It is obtained from the 5M company. It is also certified for aviation use, for cars and motorcycles bodywork construction, for universal use, and it is nonylphenolfree. The mixing ratio is 100: 40 (resin: hardener). This lamination system is certified for applications and lamination with glass, carbon, or Kevlar fabrics. Letoxide resin is made based on dian epoxy resin modification. The recommended processing temperature is $20-25^{\circ} \mathrm{C}$. Temperature higher than recommended shortens the time for processing the mixture. Lower or higher dose of hardener does not accelerate or slow down the curing of the mixture, but it will cause imperfect curing and deterioration of mechanical properties.

Wax separator Formula five vax: This wax separator for universal use is made of a mixture of carnauba with special hydrocarbon-based waxes with modern polymers. It serves to make it easier to remove components from the mould. PVA Liquid Separator - partall coverall film: Water-based liquid polyvinyl alcohol PVA separator is a separator that forms a film between the composite and the mould. [13].

\section{Technological Procedure}

The design of the body itself is based on the modified design of the Fender Stratocaster model. The design of the cavities, the holes had to be modified so that the resulting components could be moulded. The moulds used are made of glass-fibre composite by manual wet lamination technology (Figure 6).

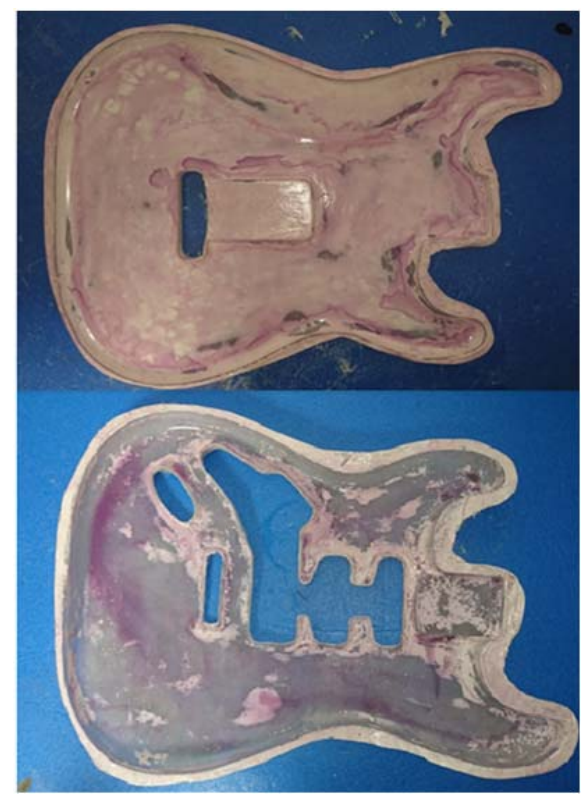

Figure 6. Laminate moulds

The whole process of saturating carbon fabrics with epoxy resin and depositing individual layers is shown in Figure 7. The epoxy resin type LETOXIT PR220 and hardener EM315 in a ratio of 100: 40 were used. First, the moulds were coated with epoxy resin. The first layer of KORDCARBON $200 \mathrm{~g} / \mathrm{m}^{2}$ twill carbon fibre bond was then placed into the moulds. Due to the final design, it was necessary to lay the first layer as best as possible so that the structure of the interweaving of fibres on the final product stood out. Next, the second layer of carbon fibre KORDCARBON $160 \mathrm{~g} / \mathrm{m}^{2}$ - plain weave was placed. Meanwhile, the third layer of carbon fibre KORDCARBON $200 \mathrm{~g} / \mathrm{m}^{2}$ - twill weave was made of fabrics with the dimension $300 \mathrm{~mm} \times 70 \mathrm{~mm}$ and $50 \mathrm{~mm} \times 50 \mathrm{~mm}$ and then laid along and laid in the corners and radii to fill them as best as possible, correspondingly. After that, the fourth layer of carbon fibre KORDCARBON $160 \mathrm{~g} / \mathrm{m}^{2}$ was laid and later the fifth layer of carbon fibre KORDCARBON $200 \mathrm{~g} / \mathrm{m}^{2}$ - twill weave was laid as well. Finally, the sixth layer of carbon fibre KORDCARBON $160 \mathrm{~g} / \mathrm{m}^{2}$ - plain weave was laid. Moreover, the last layer was made of fabrics about $50 \mathrm{~mm} \times 50 \mathrm{~mm}$ and used for additional reinforcement of critical areas around the neck, bridge and of places where other electronics and hardware components of the guitar will be fitted with screws. 


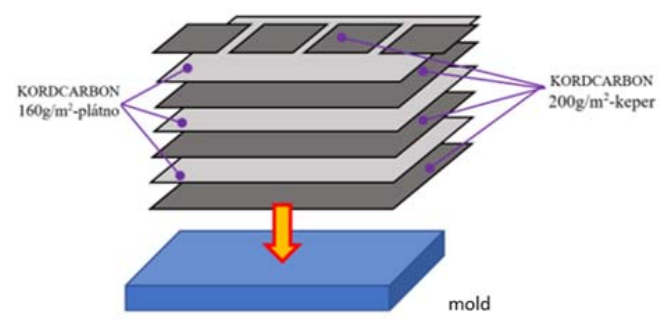

Figure 7. Composition of carbon composite in mould

A layer of perforated foil was placed on the laminated material and an absorbent fabric was applied to it as well. By applying a vacuum, the fabric absorbs excess epoxide and excess air is released from the material (Figure 8). The individual layers of carbon fabric are pressed against each other and the walls of the mould, thus copying its shape.

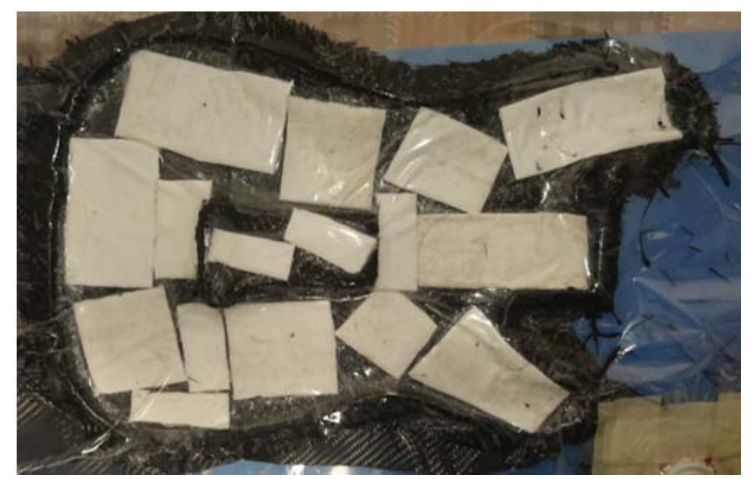

Figure 8. Prepared part of the mould

The manufacturer specifies the curing time for this type of resin at room temperature to 24 hours. After 24 hours, the component was ready and removed from the mould. The components were modified by sanding with 180,280 grit sandpaper. Excess material on the parts was removed to copy the edge of the mould (Figure 9).

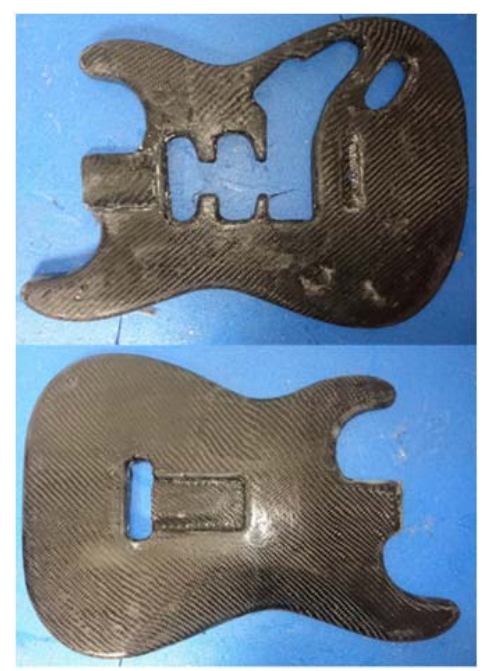

Figure 9. Modified parts removed from the mould
For the body of the guitar to function as a whole, it is necessary to connect the carbon parts of the upper and lower part. The parts were glued with Pattex epoxy universal $12 \mathrm{ml}$ epoxy adhesive.

Surface preparation: The next step was to prepare the surface for the varnish. Polyester body sealant with carbon fibre was used for small defects and a visible transition between the upper and lower part. The entire surface and any defects were sanded with fine sandpaper with a grain size of 500 then 1500 . The entire surface was dusted and degreased with acetone C6000.

The surface treatment aimed to approach the design of painting electric guitars from the $70 \mathrm{~s}$ and 80 s of the $20^{\text {th }}$ century. Such a colour adjustment is also called (silver, sun, cherry, lemon) burst according to the colours used and this will help the colour and structure of the wood stand out. In the case of a carbon guitar, it is necessary to preserve the visible structure of the carbon fibres and to cover the transition between the joined components in black. Therefore, the edges and a part of the front and back were sprayed in matt black. After drying, the entire guitar was sprayed with a hard glossy twocomponent clear varnish. After 60 hours, the varnish hardened, and the entire surface was polished with a hand polisher with a foam polishing wheel and polishing abrasive paste (Figure 10).

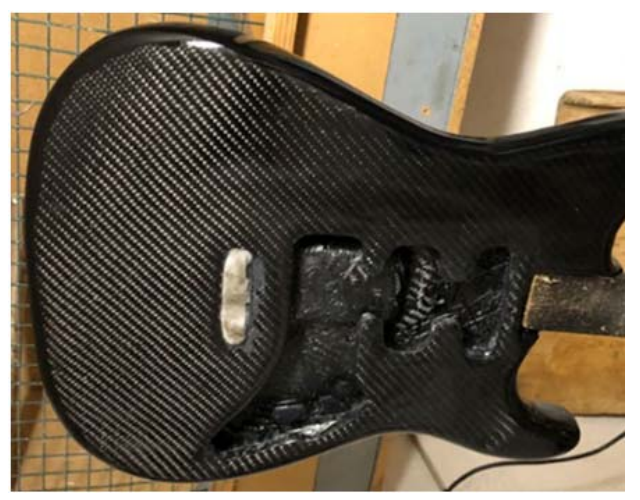

Figure 10. Final surface treatment

\section{Completion of the Guitar}

Mounting the guitar neck is as follows. A Fender Clasic Series 50s Stratocaster guitar neck was used (Figure 11). The material used for guitar completion was Fluted maple, 21 guitar frets, zero frets $42 \mathrm{~mm}$ and the neck scale of the guitar is $648 \mathrm{~mm}$. The tuning mechanisms were Fender 70s type, and it was connected to the body with $5 \times 35 \mathrm{~mm}$ screws. 

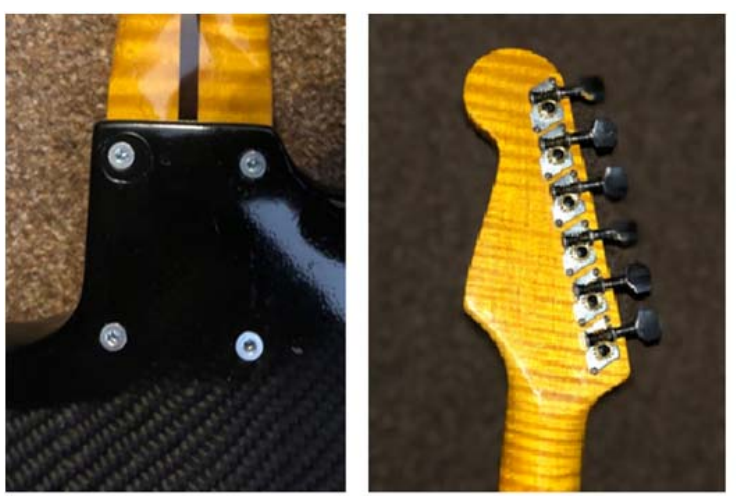

Figure 11. Detailed visualization of the guitar neck

The Fender Tremolo Vintage bridge was singlereversible made of nickel-plated steel. The rear block is created from aluminium alloy.

The body of the guitar (Figure 12) can be fitted with virtually any combination of pickups and electronics. Selected types were Fender Hot Noiseless, 5-position switch electronics, 1x volume, and $2 \mathrm{x}$ tonal aperture. The electronics are mounted in a carbon fibre pickguard.

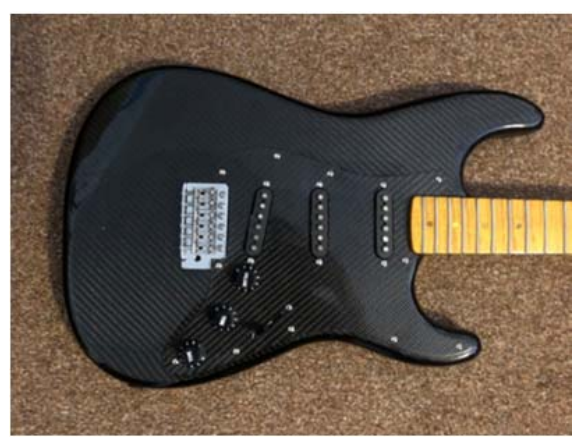

Figure 12. Mounted guitar body

The guitar is tuned to the standard tuning $(\mathrm{E}, \mathrm{A}, \mathrm{D}$, $\mathrm{g}, \mathrm{h}, \mathrm{e}$ ) and set to use strings of 009-042 hardness.

After the final adjustment of the guitar, guitar neck tunes in full and the electronics of the pickup works (Figure 13).

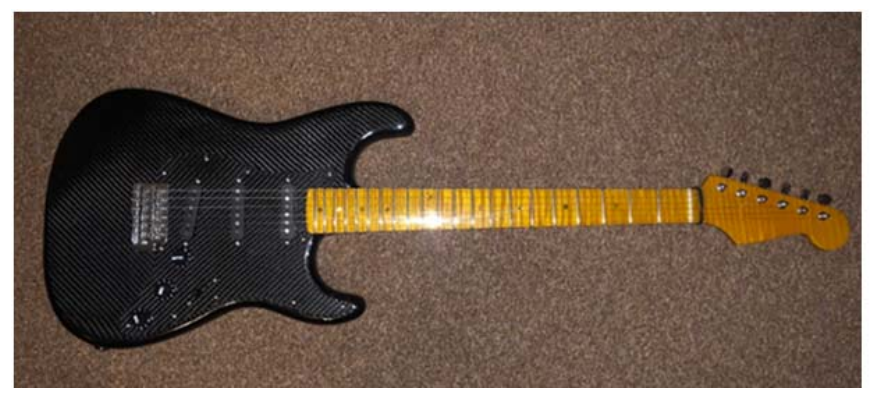

Figure 13. Completed guitar

\section{Conclusion}

The advantage of the used Vacuum Bag Molding (VBM) technology is that it is affordable and simple. VBM is suitably selected for small series production. By utilizing a vacuum, it is possible to achieve a lower porosity of the material. Production is lengthy, which means it is not possible to produce a complex shape from one piece. VBM generates a large amount of waste (vacuum bags, separation layers, and suction fabrics). On the mould side, a surface finish was good enough but on the bag side, it was less good.

The carbon composite gives the guitar the following properties: mainly weight reduction, resistance of the material to temperature fluctuations and strength. The sound could be compared to semiacoustic guitars. In the following text, there is a comparison of guitar composite body and wooden body weight.

- The net bodyweight of the composite body is $785 \mathrm{~g}$;

- The total weight of the guitar produced with a carbon fibre body is $1900 \mathrm{~g}$;

- An ash wooden body is $1720 \mathrm{~g}$;

- An ash model weighs about $3600 \mathrm{~g}$.

Acknowledgement

This research was supported by grants KEGA 018TUKE-4/2021 and VEGA 1/0080/20.

\section{References}

[1]. Murčinková, Z., Živčák, J., \& Zajac, J. (2020). Experimental study of parameters influencing the damping of particulate, fibre-reinforced, hybrid, and sandwich composites. International Journal of Materials Research, 111(8), 688-697.

[2]. Knapčíková, L., Behúnová, A., \& Behún, M. (2020). Using a discrete event simulation as an effective method applied in the production of recycled material. Advances in Production Engineering \& Management, 15(4), 431-440.

[3]. Mitalova, Z., Duplakova, D., Mital, D., Litecka, J., Dedic, V., \& Sukic, E. (2020). Monitoring Of Surface Integrity of $\mathrm{Wpc}$ Materials Base on Evaluation Selected Surface Topography Parameters. International Journal for Quality Research, 14(3).

[4]. Jozef, Zajac., Ondrej, P., Svetlana, R., Darina, D., \& David, G. (2020). Hardness Testing of Polymer Concrete Castings by Schmidt Hammer. Materials Today: Proceedings, 22, 293-299.

[5]. Electric guitar.(2021). Retrieved from: https://www.encyclopedia.com/literature-andarts/performing-arts/music-history/electric-guitar [accessed: 10 March 2021]. 
[6]. Invention, (2021). Retrieved from:

https://web.archive.org/web/20180824234551/http://i nvention.si.edu/invention-electric-guitar/p/35-

invention [accessed: 12 Marc 2021].

[7]. Smith, R. R. (1987). The history of rickenbacker guitars. Centerstream Publications.

[8]. Guitar construction and components. (2021). Retrieved from:

http://www.lakshmansruthi.com/profilesmusic/guitarconstruction-and-components.asp [accessed: 15 March 2021].

[9]. laksmansruthi, Guitar construction and components, (2021). Retireved from: http://www.lakshmansruthi.com/profilesmusic/guitarconstruction-and-components.asp [accessed: 20 March 2021].
[10]. Manufacturing and assembly. (2021).

Retrieved from:

http://compositesuniversal.com/manufacturing-6.html [accessed 25 March 2021].

[11]. Kender, Š.: Manufacturing technologies of composites (sk), (2021)., Retrieved from:

https://www.sjf.tuke.sk/transferinovacii/pages/archiv/t ransfer/33-2016/pdf/188-191.pdf [accessed: 20 April 2021].

[12]. Yunus, S., Salleh, Z., Aznan, M. A., Berhan, M. N., Kalam, A., Rashid, A. A., \& Wong, F. R. (2014). Impacted of Vacuum Bag Woven Kenaf/Fiberglass Hybrid Composite. In Applied Mechanics and Materials (Vol. 660, pp. 572-577). Trans Tech Publications Ltd.

[13]. Kordcarbon 200g/m2 Keper, (2021). Retrieved from: https://eshop.5mslovakia.sk [accessed: 20 April 2021]. 